Thermodynamic Analysis Of Pure And Impurity Doped Pentaerythritol Tetranitrate Crystals Grown At Room Temperature

R. Pitchimani, W. Zheng, S. Simon, L. Hope-Weeks, A. K. Burnham, B. L. Weeks

June 2, 2006

NATAS 34th Annual conference Bowling Green, KY, United States August 6, 2006 through August 9, 2006 
This document was prepared as an account of work sponsored by an agency of the United States Government. Neither the United States Government nor the University of California nor any of their employees, makes any warranty, express or implied, or assumes any legal liability or responsibility for the accuracy, completeness, or usefulness of any information, apparatus, product, or process disclosed, or represents that its use would not infringe privately owned rights. Reference herein to any specific commercial product, process, or service by trade name, trademark, manufacturer, or otherwise, does not necessarily constitute or imply its endorsement, recommendation, or favoring by the United States Government or the University of California. The views and opinions of authors expressed herein do not necessarily state or reflect those of the United States Government or the University of California, and shall not be used for advertising or product endorsement purposes. 


\title{
Thermodynamic Analysis Of Pure And Impurity Doped Pentaerythritol Tetranitrate Crystals Grown At Room Temperature
}

\author{
Rajasekar Pitchimani ${ }^{1}$, Wei Zheng ${ }^{1}$, Sindee Simon ${ }^{1}$, Louisa Hope-Weeks ${ }^{2}$, Alan K Burnham ${ }^{3}$, \\ Brandon L Weeks, ${ }^{1, *}$ \\ ${ }^{1}$ Chemical Engineering, Texas Tech University \\ Box 43121, Lubbock TX 79409-3121 \\ ${ }^{2}$ Department of Chemistry and Biochemistry, Texas Tech University \\ Box 41061, Lubbock TX 79409-1061 \\ ${ }^{3}$ Chemistry and Materials Science, Lawrence Livermore National Laboratory \\ Box 808, Livermore, CA 94551-0808
}

\begin{abstract}
Pentaerythritol tetranitrate (PETN) powders are used to initiate other explosives. During longterm storage, changes in powder properties can cause changes in the initiation performance. Changes in the morphology and surface area of aging powders are observed due to sublimation and growth of PETN crystals through coarsening mechanisms, (e.g. Ostwald ripening, sintering, etc.). In order to alleviate the sublimation of PETN crystals under service conditions, stabilization methods such as thermal cycling and doping with certain impurities during or after the crystallization of PETN have been proposed.

In this report we present our work on the effect of impurities on the morphology and activation energy of the PETN crystals. The pure and impurity doped crystals of PETN were grown from supersaturated acetone solution by solvent evaporation technique at room temperature. The difference in the morphology of the impurity-doped PETN crystal compared to pure crystal was examined by optical microscopy. The changes in the activation energies and the evaporation rates are determined by thermogravimetric (TGA) analyses. Our activation energies of evaporation agree with earlier reported enthalpies of vaporization. The morphology and activation energy of PETN crystals doped with $\mathrm{Ca}, \mathrm{Na}$, and Fe cations are similar to that for pure PETN crystal, whereas the Zn-ion-doped PETN crystals have different morphology and decreased activation energy.
\end{abstract}

\section{INTRODUCTION}

High surface area powders of PETN carefully packed at a specific density, (typically on the order of $5000 \mathrm{~cm}^{2} / \mathrm{g}$ to $30,000 \mathrm{~cm}^{2} / \mathrm{g}$ ), are successfully used as an initiating explosive. However changes in the composition and surface area within aging explosive components are observed due to sublimation and growth of PETN crystals through coarsening mechanisms, (e.g. Ostwald ripening and surface diffusion). Several external and internal factors have been proposed to affect the crystal growth rate and crystal morphology. Internal factors include the crystal structure, dislocation and other defects in the crystal and the external factors include those imposed on the crystal by the crystallization conditions defined by growth parameters (temperature, supersaturation etc) and introduction of impurities. These internal and external factors can control the growth processes as well as the aging processes of PETN. Explanations of the mechanisms that control crystal morphology and shape have thus far been at best qualitative. In order to alleviate the sublimation of PETN crystals under service conditions, doping with certain impurities during the crystallization of PETN has been proposed.

There have been numerous reviews on the effects of impurities on crystal habit, crystal growth and on the mechanisms of adsorption of impurities. Buckley surveyed the literature prior to 1950 on the habit modification of crystal by impurities (1) and after that there have been many reviews on the effects of impurities on crystal habit and on crystal growth (2-5). There have been a few studies on the crystal morphology engineering by the tailor-made impurities $(6,7)$, and there have been a few attempts to model the morphology of growing organic crystals in the presence of the tailor-made impurities $(8,9)$. 
There have been few studies on the thermal stability of PETN crystals. Using Differential Scanning Calorimetry (DSC) technique, Rogers and Dinegar (10) studied the variations in the heat of fusion of PETN for three different crystal habits, namely tetragonal, needle type and superfine type containing irregular plates. They measured the variation of heat of fusion for different surface areas of each of the habit obtained by ball-milling and ultrasonic grinding. They also added $1 \%$ tripentaerythritol octanitrate (triPEON) to all the habits and determined the change in heat of fusion. They concluded that the variation in heat of fusion is not a function of surface area or purity, but a large amount of impurity tends to reduce the heat of fusion. They explained this as due to the presence of impurities that form PETN II (a metastable polymorph state of PETN formed when PETN is crystallized rapidly from a super cooled melt) retards the conversion to PETN I. X-ray diffraction studies also showed that larger amounts of impurity stabilized PETN II on precipitation from solution. Therefore they argued that the change in heat of fusion is a result of crystal imperfection and is not due to change in surface area (10).

There are a few earlier papers on vapor pressure and evaporation rates. Eiceman et al. (11) studied the evaporation rates and activation energies of 2,4,6-trinitrotoluene (TNT), cyclotrimethylenetrinitramine (RDX) and PETN in the temperature range $79-150^{\circ} \mathrm{C}$ using a prototype vapor generator that has been calibrated to a mass standard from National Institute of Standards and Technology (NIST). For PETN the measured mass output rates increased with increase in temperature. From IMS/MS studies they found that the carrier gas contains pure PETN and significant amount of decomposed product of PETN (11) and attributed it to the increased difference between the calculated and measured output rates. Lau et al. (12), Behrens (13), and Meyer et al. (14) report the temperature dependence of the vapor pressure.

In this paper we present our results for the effect of doping ( $\mathrm{Fe}, \mathrm{Na}, \mathrm{Ca}$ and $\mathrm{Zn}$ ) cation on the crystal morphology and evaporation rate of PETN crystals. We have used TGA technique to evaluate the change in the Arrhenius parameters for evaporation and used the optical microscope to study the change in morphology upon doping the PETN crystals.

\section{EXPERIMENTAL}

Pure and impurity doped PETN crystals were produced by using solvent evaporation technique. The PETN powder was supplied by Lawrence Livermore National Laboratory. A PETN solution was prepared by dissolving the PETN powder in acetone to make supersaturated solution. For preparing the doped PETN crystals, granules of $\mathrm{Ca}\left(\mathrm{NO}_{3}\right)_{2} 4 \mathrm{H}_{2} \mathrm{O}$ (MCB Manufacturing Chemists Inc., Cincinnati, $\mathrm{OH}$ ), $\mathrm{Na}\left(\mathrm{NO}_{3}\right)$ (Mallinckrodt Inc., Paris, Kentucky), $\mathrm{Fe}\left(\mathrm{NO}_{3}\right)_{3} 9 \mathrm{H}_{2} \mathrm{O}$ (J.T. Baker Chemical Co. Phillipsburg, N.J.) and $\mathrm{Zn}\left(\mathrm{NO}_{3}\right)_{2} 6 \mathrm{H}_{2} \mathrm{O}$ (Mallinckrodt Baker Inc., Phillipsburg, N.J.) were dissolved in acetone in separate vials and PETN powder was dissolved in the each of these solution so that the impurity concentration in the final solution was 100ppm. All the doped PETN crystals were grown at room temperature.

Thermogravimetric analyses were carried out with a PerkinElmer TGA-7 instrument. Before the introduction of the crystal into the TGA apparatus, the optical images were taken by Olympus SZH stereomicroscope. The optical image was used to calculate the surface area of the sample. Before the experiment, the TGA was calibrated using standard temperature calibration reference material Alumel (Curie point transition temperature is $154^{\circ} \mathrm{C}$ ). Preliminary TGA experiments on pure PETN showed that there is no loss of weight observed on isothermal heating until $100^{\circ} \mathrm{C}$. Hence the samples (pure and the impurity-doped PETN) were heated from 105 to $135^{\circ} \mathrm{C}$ in steps of $5^{\circ} \mathrm{C}$ and were maintained 2 hours at each temperature. The rate of heating was always maintained at $40^{\circ} \mathrm{C} / \mathrm{min}$. Nitrogen is used as the purge gas for both sample and the balance. During the isothermal heating the weight of the sample is measured as a function of time. From this the rate of change in weight was calculated. The calculated rate of weight change at each temperature was normalized to the surface area of the crystal. 


\section{RESULTS AND DISCUSSION}

Figure 1 shows the optical images of pure as well as doped PETN crystals. The optical images of $\mathrm{Ca}, \mathrm{Na}$ and Fe-doped PETN crystals look similar to that of pure PETN. Pure PETN has tetragonal structure. The top face (the (110) face) of the all crystals except Zn-ion doped crystal is flat and smooth similar to that of pure PETN. The Zn doped PETN crystal differs from the pure as well as other doped crystals. The top face (the (110) face) of the Zn-ion doped crystal is not flat and is not smooth and seems to have many steps (figure 1). This implies that the growth pattern of PETN is changed by adding Zn-ion.
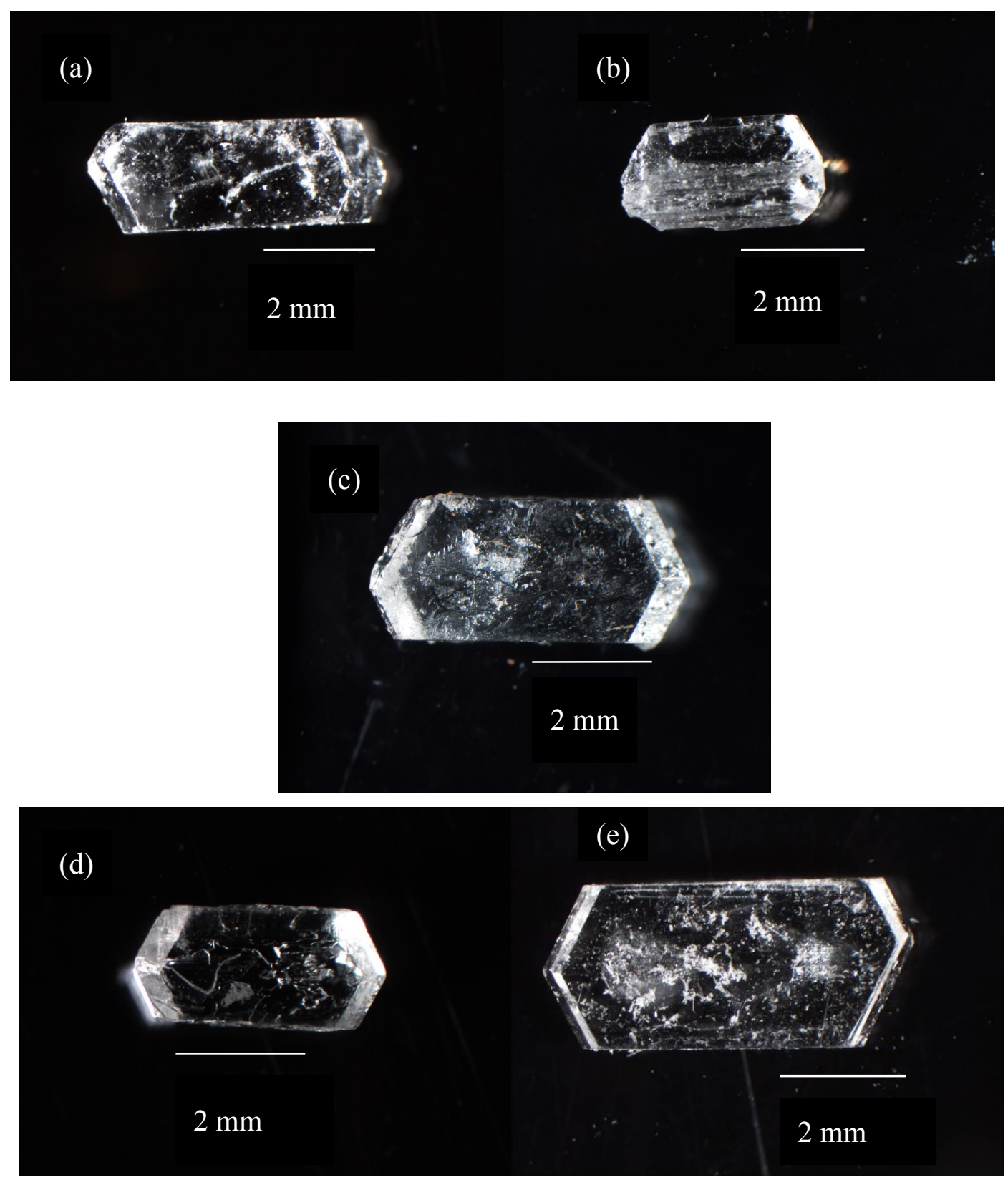

Figure 1. Optical images of crystal of (a) Na-ion doped PETN; (b) Zn-ion doped PETN; (c) Pure PETN; (d) Ca-ion doped PETN and (e) Fe-ion doped PETN

Li et al (15) noticed a habit change of $\mathrm{KCl}$ crystals from cubic to octahedral due to the precipitation of $\mathrm{Pb}^{3+}$ ions as $\mathrm{PbCl}_{2}$ crystallites preferentially along the $<110>$ steps of growth layers on 
the $\{100\}$ face. They established this habit change through in-situ and ex-situ surface microtopographs of growing and etched $\{100\}$ and $\{111\}$ faces of $\mathrm{KCl}$ crystals by using differential interference contrast microscopy. This kind of mechanism of poisoning of steps on the $\{100\}$ faces of $\mathrm{KCl}$ crystals by the $\mathrm{PbCl}_{2}$ impurity is also observed by atomic force microscope (AFM) at the nanometer scale on calcite by HEDP (1-hydroxyethylidene-1,1-diphosphoric acid), SHMP (sodium hexametaphosphate) and NaTP (sodium triphosphate) impurities (16). For the case of calcite, they saw poisoning by inorganic phosphates. Adsorption occurred directly at the steps above a threshold concentration, and further growth was inhibited until the poison was removed. HEDP and SHMP modified the re-growth morphology, leading to spicular growth domain.

There are models that describe the effects of impurities on crystal growth processes based on the concept of adsorption of impurities at kinks, ledges and terraces of the growing crystal (17-19). These models have been surveyed recently and the experimental data on crystal growth rates are compared with their predictions (2). In Zn-ion doped PETN, the changes in the morphology seen by optical microscopy are not enough to define the mechanism of changes on the morphology. The present paper concentrates more on the changes in the overall vapor pressure and activation energy (discussed in the following) with the introduction of impurity ions, and we have not carried out the detailed studies on these faces. However the fact that the morphology changes with the doping of Zn-ion suggests that the evaporation rate will change due to a change in activation energy, frequency factor, or both.

The typical plot of rate of weight loss per unit surface area as function of inverse of temperature for pure as well as Fe- and Zn-doped PETN crystals are shown in figure 2. Ca and Na doped crystals are not shown, as they are similar to Fe doped crystal.

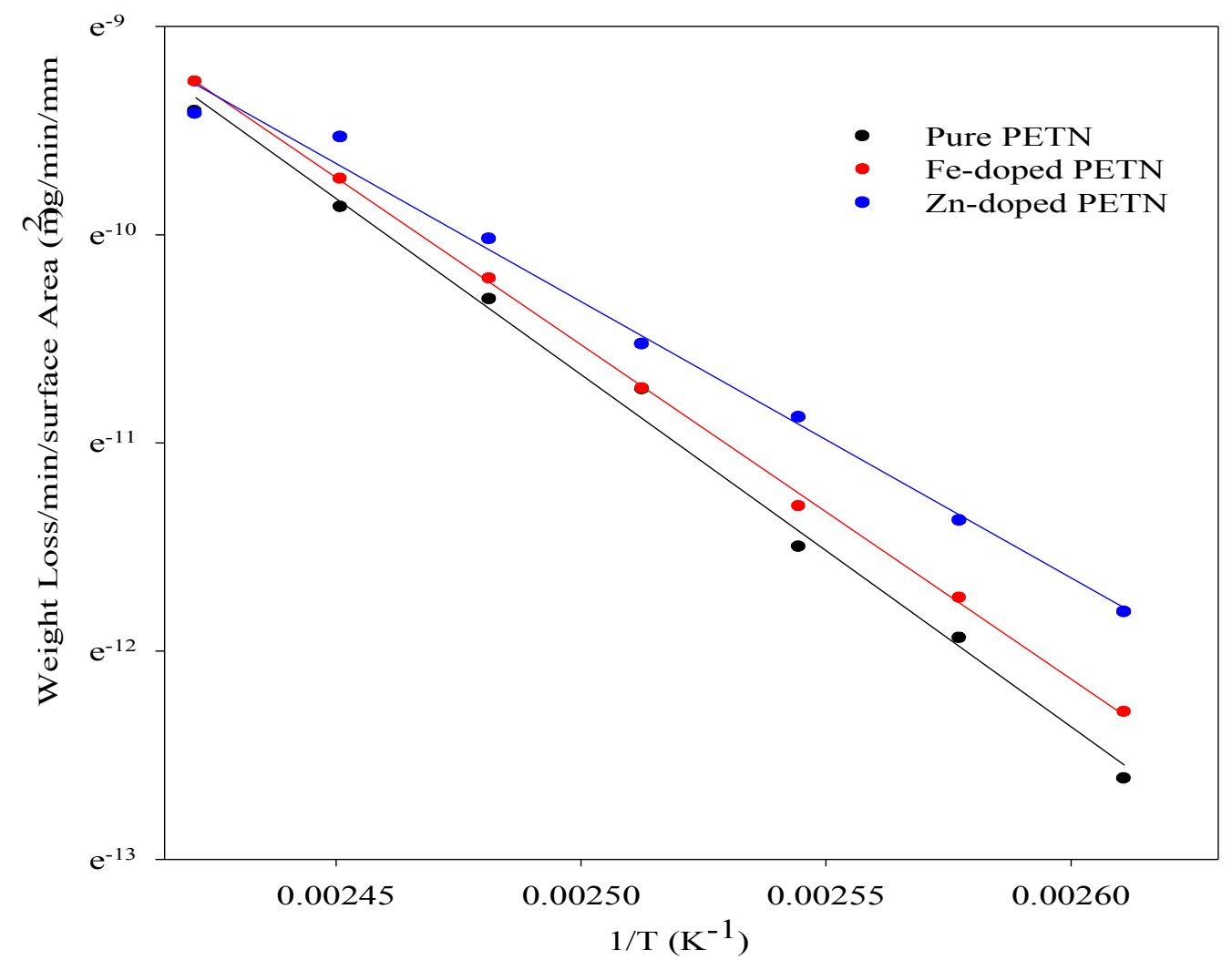

Figure 2. Rate of weight loss per unit surface area as a function of inverse of temperature for pure, Fe-ion and $\mathrm{Zn}$-ion doped PETN crystals

The evaporation rate for Zn-ion doped PETN is significantly more than that of pure PETN. Evaporation rates for all the crystals increased with temperature. Linear fits show that the differences in 
evaporation rate for the doped and pure PETN crystals disappear as the temperature approaches the melting point of $140^{\circ} \mathrm{C}$.

Table 1 gives the Arrhenius parameters calculated from slope and the intercept of the TGA plots for the pure and impurity-doped PETN crystals. The activation energy of the Zn-ion doped PETN is less than that of pure PETN, whereas the activation energies of Fe, $\mathrm{Ca}$ and Na-ion doped PETN are close to that of pure PETN. The parameter A for Zn-doped crystal is found to be almost 2 orders less than that of pure PETN. The decrease in both A and E for crystals grown in Zn-ion doped solutions together cause a decrease in the stability of PETN as measured by its higher evaporation rate.

Our activation energy for evaporation agrees with earlier measurements of the enthalpy of evaporation from the temperature dependence of the vapor pressure by Lau et al. (12), Behrens (13), and Meyer et al. (14). This is understandable, because the molar flux (J) away from a surface in presence of a foreign gas is given by

$$
\mathrm{J}=(\mathrm{p} \text { D) } / \mathrm{zRT}
$$

where $\mathrm{p}$ is the vapor pressure, $\mathrm{D}$ is the mutual diffusion constant for the molecule of interest in the foreign gas, and $\mathrm{z}$ is the distance from the evaporating surface where the partial pressure of the evaporating gas drops to zero. However, our activation energy is substantially higher than the 14.4 $\mathrm{kcal} / \mathrm{mol}$ reported by Dionne et al. (20) and substantially less than the $55.7 \mathrm{~kJ} / \mathrm{mol}$ reported by Eiceman et al (11).

Table 1. Values of Arrhenius parameters A and E (activation energy) of pure and Fe, $\mathrm{Zn}, \mathrm{Na}$ and Ca doped PETN.

\begin{tabular}{|c|c|c|}
\hline & \multicolumn{2}{|c|}{ Arrhenius parameters } \\
\hline & A (mg/mm $\left.{ }^{2} / \mathbf{m i n}\right) \mathbf{~} \mathbf{1 0}^{\mathbf{1 2}}$ & E (kcal/mol) \\
\hline Pure PETN & 79.4 & 35.2 \\
\hline Fe-doped PETN & 357.4 & 35.7 \\
\hline Zn-doped PETN & 0.1 & 28.7 \\
\hline Na-doped PETN & 24.0 & 32.2 \\
\hline Ca-doped PETN & 10.2 & 32.6 \\
\hline
\end{tabular}

Although we have not measured the actual concentrations of the impurities in the crystals, crystals grown in $\mathrm{Zn}$-ion doped solutions have a lower stability based on their higher evaporation rate. Additional studies of the mechanisms of the impurity adsorption, including the use of atomic force microscopy, are planned in future. This will enable us not only to control the morphology of the PETN crystals but also to achieve more stable PETN. 


\section{AKNOWLEDGEMENT}

This work was performed under the auspices of the U. S. Department of Energy by University of California, Lawrence Livermore National Laboratory, under Contract No. W-7405-Eng-48.

\section{REFERENCES}

1. H.E. Buckley, Crystal growth, Wiley New York 1951.

2. R.J. Davey, in Industrial Crystallization 78 E.J. de Jong and S.J. Jancic (ed.), North-Holland, Amsterdam (1979) p.169.

3. B. Simon and R.J. Boistelle, J. Cryst. Growth, 1981, 52, 779.

4. $\quad$ K. Sangwal, J. Cryst. Growth, 1993, 128, 1236.

5. K. Sangwal, Prog. Crystal Growth and Charact. 1996, 32, 3.

6. I. Weissbuch, L.J.W. Shimon, E.M. Landau, R. Popovitz-Biro, Z. Berkovitch-Yellin, L. Addadi, M. Lahav and L. Leiserowitz, Pure. \& Appl. Chem., 1986, $58,947$.

7. Z. Berkovitch-Yellin, J. van Mil, L. Addadi, M. Idelson, M. Lahav and L. Leiserowitz, J. Am. Chem. Soc., 1985, 107, 3111.

8. G. Clydesdale, K.J. Roberts and R. Docherty, J. Cryst. Growth, 1994, 135, 331.

9. G. Clydesdale, K.J. Roberts, K. Lewtas and R. Docherty, J. Cryst. Growth, 1994, 141, 443.

10. $\quad$ R.N. Rogers and R.H. Dinegar, Thermochimica Acta, 1972, 3, 367.

11. G.A. Eiceman, D. Preston, G. Tiano, J. Rodriguez and J.E. Parmeter, Talanta, 1997, 45, 57.

12. K.H. Lau, D.L. Hilderbrand, S.Crouch-Baker, A. Sanjurjo, J. Chem. Eng. Data, 2004, 49, 544.

13. R. Behrens, "Update on the Analysis of Thermally and Chemically Stabilized PETN powders", Presented at JOWOG Focused Exchange Meeting, May 12-14, 2003, Albuquerque, NM, Sandia National Laboratories.

14. R. Meyer, J. Kohler and A. Homburg, Explosives, 5th ed., Wiley, 2002, p. 253.

15. L. Li, K. Tsukamoto and I. Sunagawa, J. Cryst. Growth, 1990, 99, 150.

16. A.J. Gratz and P.E. Hillner, J. Cryst. Growth, 1993, 129, 789.

17. G.M. Bliznakov, Bull. Acad. Sci. Bulg. Ser. Phys., 1954, 4, 135.

18. G. Bliznakov, E. Kirkova, Krist. Tech., 1969, 4, 331.

19. N. Canbrera, D.A. Vermilyea in Growth and Perfection of Crystals, R.H. Doremus, B.W. Roberts and D Turnbull (Eds), Wiley, New York, 1958, p. 393.

20. B.C. Dionne, D.P. Rounbehler, E.K. Achter, J.R. Hobbs and D.H. Fine, J. Energetic Mater., $1986,4,447$. 